DOI: http://dx.doi.org/10.18764/2358-4319.v13n2p270-292

\title{
A educação como contraponto das políticas neoliberais de fratura social
}

\author{
Maria José Pereira de Oliveira Dias ${ }^{1}$ \\ Maria Esperança Fernandes Carneiro ${ }^{2}$
}

\section{RESUMO}

Este artigo apresenta as estratégias históricas do modelo econômico neoliberal e as arbitrariedades políticas instituídas nesse tipo de economia que gera graves consequências contra a classe trabalhadora brasileira e amplia as desigualdades sociais. Ao problematizar essas questões, foi necessário analisar e discutir demandas referentes às políticas neoliberais e suas arbitrárias imposições ao trabalhador. A partir desse fundamento, percebemos que é preciso assumir o risco de compreender a história como fundamento e enfrentamento das mazelas provocadas pelo presente sistema neoliberal que é um grande impositor das desigualdades sociais e constituidor de direitos que preservam a acumulação de capital da classe dominante.

Palavras-chave: Neoliberalismo. Classe trabalhadora. Educação.

\section{Education as Counterpoint for Neoliberals Politics for Social Fracture}

\begin{abstract}
This article features the historical strategies of the neoliberal economic model and the political arbitrariness instituted in this type of economy, which generates serious consequences against a Brazilian labor class and wide social inequalities. Therefore, those questions are analyzed

1 Mestre em Educação no PPGE da Pontifícia Universidade Católica de Goiás - PUC Goiás. Doutoranda em Educação no PPGE da Pontifícia Universidade Católica de Goiás - PUC Goiás. Professora no Departamento de Educação Infantil/CEPAE/UFG. Bolsista FAPEG, e Membro do Grupo de Pesquisa em Políticas Educacionais e Gestão Escolar - GPPEGE/PUC Goiás - www. gppege.org.br. ORCID: htpp://orcid.org/0000-0002-95897847.Email: mjpgoster@gmail.com

2 Doutora em Educação pela Pontifícia Universidade Católica de São Paulo. Professora do Programa de Pós-Graduação Stricto Sensu em Educação da Pontifícia Universidade Católica de Goiás, na Linha de Pesquisa: Estado, Instituições e Políticas Educacionais e ao Grupo de Pesquisa em Políticas Educacionais e Gestão Escolar - GPPEGE/PUC Goiás - www.gppege.org. br. ORCID:http://orcid.org/0000-00027272-6666. E-mail: esperancacarneiro@outlook.com.
\end{abstract}


and discussed based on neoliberal policies against the workman. From this foundation, we perceive that it is necessary to take on or to understand the history as a foundation and confrontation of bad ones caused by the present neoliberal system that is a great diffuser of social inequalities and constituent of directs that preserve the riches of the dominant class

Keywords: Neoliberalism. Class worker. Education.

\section{La Educación como Contrapunto de las Políticas Neoliberales de Fractura Social}

\section{RESUMEN}

Este artículo presenta las estrategias históricas del modelo económico neoliberal y las arbitrariedades políticas instituidas en dicha economía, que genera graves consecuencias contra la clase trabajadora brasileña y amplía las desigualdades sociales. Al problematizar esas cuestiones, fue necesario analizar y discutir demandas referentes a las políticas neoliberales y sus arbitrarias imposiciones al trabajador. Con base en ello, percibimos que es necesario asumir el riesgo de comprender la historia como fundamento y enfrentamiento de los daños provocados por el presente sistema neoliberal que es un gran impositor de las desigualdades sociales y constituidor de derechos que preservan la acumulación de capital de la clase dominante,

Palabras-clave: Neoliberalismo. Clase trabajador. Educacion.

\section{Introdução}

Este artigo relaciona-se aos conhecimentos problematizados no decorrer da Tese de Doutorado em Educação da Pontifícia Universidade Católica de Goiás. Destaca as principais artimanhas do modelo econômico neoliberal e as consequências dessa política para a classe trabalhadora, bem como os seus impactos arbitrários no que tange aos trabalhadores docentes.

Assim, para analisar e problematizar as questões referentes às políticas neoliberais e suas arbitrárias imposições ao trabalhador, desenvolvemos uma pesquisa bibliográfica nos aportando nas reflexões apresentadas pelos seguintes autores: Anderson (1995), Chauí (2011), Bastos 
e Cardozo (2014), Fontes (2020), Forrester (1997), Sennett (1999), Freire e Freire (2001), Ramalho (2018), Teixeira e Coutinho (2012).

A história nos revela que o neoliberalismo emergiu na Europa e América do Norte, após a II Guerra Mundial, em regiões em que o capitalismo possuía grande força econômica e política. $\mathrm{O}$ seu surgimento se deu a partir de um movimento teórico e político opositor ao Estado de Bem-Estar Social ${ }^{3}$. A justificativa para tal oposição era de que o igualitarismo fomentado pelo "Estado de bem-estar" não contribuía para a "liberdade dos cidadãos e a vitalidade da concorrência, da qual dependia a prosperidade de todos". O grupo argumentava, também, que a desigualdade era de certo modo um valor positivo e importante para a nova sociedade que estava se constituindo pós-Segunda Guerra Mundial (ANDERSON, 1995, p. 09-10).

As ideias neoliberais ganharam força com o início da crise econômica de 1970, que se caracterizou por forte recessão na qual o mundo capitalista experimentava taxas de inflação elevadas e atreladas ao baixo crescimento econômico, ou seja, de realização do lucro. De acordo com Ramalho (2018, p. 303),

\begin{abstract}
O pensamento neoliberal, como o nome indica, se baseia no pensamento político-econômico do liberalismo clássico; defende o reino do mercado nas relações sociais, a privatização, o individualismo, e um governo não intervencionista no mercado livre. A função do estado se resume na defesa contra inimigos externos e a manutenção da ordem interna através de aparatos policiais e legais, incluindo um clima econômico de proteção aos interesses capitalistas.
\end{abstract}

Pode-se constatar que o modelo econômico neoliberal é hegemônico no mundo ocidental com sua política do máximo de recursos e investimentos para o capital e o mínimo para as ações sociais; e que este tem ampliado seus tentáculos via programas, sendo sua atuação no mundo, significativa. Desse modo, promovem privatizações infindáveis, provocam crises financeiras e desigualdades sociais, mas, ainda assim,

3 Segundo Marilena Chauí, o Estado de Bem-Estar Social possuía três características singulares. A primeira estava relacionada ao sistema fordista com importantes indústrias detentoras das atividades econômicas, com produções de matérias-primas e toda distribuição "no mercado de consumo" e que controlavam com planejamentos sistematizados a organização do trabalho, a produção de estoques e "formação de preços dos produtos". A segunda contribuía com os encaminhamentos dos indivíduos ao mercado de trabalho. E, por fim, "monopólios e oligopólios que, embora transnacionais ou multinacionais, tinham como referência reguladora o Estado nacional (CHAUÍ, 2011, p. 311). 
nos países europeus - onde os trabalhadores são organizados -, não conseguiram acabar com o Estado de bem-estar social, mesmo com todas as estratégias de redução de gastos no âmbito social.

A partir de algumas experiências neoliberais em países próximos ao Brasil como o Chile, é pertinente pensar que as ditaduras militares vigentes nas décadas de 1960 a 1980, que tomaram a América Latina, constituíram-se em um dos mecanismos usados para impor coercitivamente aos povos a convivência com a pauperização criada pelas mais drásticas políticas neoliberais. O que se sabe é que, de acordo com Anderson (1995), o neoliberalismo é um processo ideológico de alcance mundial, ou seja, com uma estrutura de ampla extensão e uma "[...] doutrina coerente, autoconsciente, militante, lucidamente decidido a transformar todo o mundo à sua imagem" (p. 21-22).

Apesar de o neoliberalismo continuar existindo como um movimento em processo de desenvolvimento com significativas experiências de fracassos econômicos e onde um dos seus resultados mais perversos conduz a sociedades cada vez mais desiguais, possui forte hegemonia mundial e as suas doutrinas não dão alternativas diferentes daquelas implantadas por suas ideologias. Para Marilena Chauí (2011, p. 317),

Por conseguinte, visto sob a perspectiva da luta po-
lítica, o neoliberalismo não é de modo algum a cren-
ça na racionalidade do mercado, o enxugamento do
Estado e o desaparecimento do fundo público. Ele é
a posição política, vitoriosa no momento, que decide
cortar o fundo público no pólo do financiamento dos
bens e dos serviços públicos, cortar o financiamento
público do salário indireto e maximizar o uso da ri-
queza pública nos investimentos exigidos pelo capi-
tal, cujos lucros não são suficientes para cobrir todas
as possibilidades tecnológicas que ele mesmo abriu.

Chauí (2011) ressalta ainda que o desaparecimento da identidade e dos direitos do bem público se deve à crise com o Estado de Bem-Estar Social que culminou na ampliação do setor privado.

Há algumas décadas o Brasil vem provando o fel extraído desse modelo econômico. O atual governo (2016), decorrente de golpe mediático/jurídico/parlamentar, com a conivência dos Estados Unidos, portanto, não eleito pelo povo (dada a sua filiação ao projeto neoliberal com medidas arbitrárias de privatizações), elevou o percentual de desempre- 
go no país, chegando a 12,4 milhões de desempregados de acordo com a Agência IBGE Notícias ${ }^{4}$ (PARADELLA, 2019).

Em reportagem recente, o Professor de Economia da Universidade Estadual de Campinas, Marcio Pochmann (2018), apresentou uma matéria na Rede Brasil Atual na qual faz uma análise acerca do cenário do governo Temer e do processo de continuidade do governo Bolsonaro em relação às políticas neoliberais. Segundo ele, esse modelo "receituário neoliberal" instituído pelos últimos governos Temer e Bolsonaro, tende a descontruir políticas de trabalho "digno pelo ganho indecente de produtividade". As propostas de reformas apresentadas nesses governos apontaram para a desregulamentação das políticas ligadas à "sustentabilidade ambiental", sobretudo autorizando a livre utilização de agrotóxicos proibidos na Europa e USA. E, ainda, para a ampliação dos processos de privatizações de instituições públicas, inclusive com agendas voltadas para a previdência social, contendo asserção de capitalização, o aumento dos "cortes" nos programas sociais que são fundamentais para combater a pobreza e a miséria que tem crescido e chegado ao ponto alarmante em que 5 milhões de crianças brasileiras passaram a viver em extrema pobreza, segundo o Jornal Valor Econômico (BÔAS, 2018). Por fim, ainda nesse cenário de propostas de mudanças, nos últimos governos, nota-se maior abertura para as políticas neoliberais e, com isso, há o agravamento resultante da privatização na "venda de metade das refinarias da Petrobras" na qual, nitidamente, o país deixará de "refinar 1,1 milhão de barris por dia", conforme informa o Diário Centro do Mundo (SOB..., 2019), visto que nessa ação arbitrária de governança o Brasil acabará não arrecadando mais de 28 milhões de dólares.

Para Chauí (2011), as formas atuais de produção do capitalismo podem ser vistas na ampliação do desemprego, no monetarismo e no capital financeiro que desvalorizam o trabalho, ampliam a terceirização e influenciam na compra de serviços, o que contribui para a fragmentação da produção, das forças produtivas e da valorização das ciências e tecnologias como agentes econômicos importantes. $O$ desaparecimento dos direitos sociais, nesse modelo econômico, com a criminalização dos movimentos sociais e a truculência da repressão, converte os trabalhadores em prestadores de serviços privados regulados pelo mercado, de modo

4 "O aumento representou a entrada de 892 mil pessoas na população desocupada, totalizando 13,1 milhões de trabalhadores nessa condição. Já a taxa composta de subutilização da força de trabalho ficou em 24,6\%, somando 27,9 milhões de pessoas, pico da série histórica iniciada em 2012" (PARADELLA, 2019). 
que as importantes e principais decisões podem ser tomadas por organismos internacionais por serem considerados detentores econômicos mundiais, como o Fundo Monetário Internacional e o Banco Mundial. O neoliberalismo ainda nos leva a submissão aos cortes de direitos sociais em função da disputa por investimentos internacionais que maximizam as desigualdades entre os países de primeiro mundo e os demais.

Dessa maneira, os dogmas constituídos pelo neoliberalismo reforçam a desvalorização e a exclusão dos trabalhadores, promovem a valorização financeira, influenciam na fragmentação do trabalho, incentivam a competição e o aligeiramento do conhecimento contemporâneo, eliminam os direitos sociais historicamente construídos, abre portas para gerências externas e descomprometidas com os problemas da sociedade atual, e, por fim, fomentam as desigualdades econômica e social entre nações.

Com base no exposto, "[...] a ideologia da competência afirma que os que possuem determinados conhecimentos têm o direito natural de mandar e comandar os demais em todas as esferas da vida social [...]" (CHAUÍ, 2011, p. 322), reforçando fortemente a divisão de classe entre aqueles que dominam por serem especialistas ou detentores de certo conhecimento, daqueles que são dominados e submissos às ordens impostas pela classe dominante. O que se vê é um processo proposital de "despolitização da sociedade", com a apresentação de conceitos puramente técnicos, não transparentes e incompreensíveis a maioria dos cidadãos, como se os seres humanos fossem invisíveis no contexto social (CHAUÍ, 2011, p. 322-323).

É uma forma de política econômica que legitima a exclusão via desmantelamento dos direitos sociais, a competição exacerbada, a privação da liberdade do ser humano de participar ativamente de sua própria vida social, bem como a marginalização e naturalização da violência entre os homens, de forma que inviabiliza a solução dos problemas sociais e contribui para a degradação humana.

Recentemente, agravando a situação acima exposta, vivemos uma pandemia ${ }^{5}$ no capitalismo e isso tem provocado péssimas condições de trabalho com o isolamento social e agudizado as contradições

5 Segundo Fontes (ENTREVISTA..., 2020) até onde sabemos, essa pandemia do novo coronavírus teve início na China, que é um país superpopuloso e que "diante do temor de expansão da doença" tomar proporções descontroladas, logo "tomou rigorosas medidas de isolamento social". Essas medidas de isolamento provocaram "a interrupção total das atividades em um dos maiores centros industriais do país, Hubei, com mais de 60 milhões de habitantes, e em sua capital Wuhan". 
que interferem a vida individual e coletiva humana. Segundo Fontes (ENTREVISTA...,2020), a pandemia do coronavírus tem incitado tensões em países desenvolvidos e demais nações capitalistas, quando em meio à crise eles se posicionam em defesa do lucro acima da vida, procurando evitar as interrupções das atividades de trabalho que podem interferir na extração do processo de produção para o capital, reduzindo-o. Para a autora, antes da crise sanitária já vivíamos outras crises capitalistas com a superprodução de capitais em forma de títulos ou valores em dinheiro, no enriquecimento desordenado de banqueiros e na exploração descarada da classe trabalhadora. Todo esse processo de mudança vinha sendo anunciado pelos economistas mundiais.

No entanto, de acordo com autora, essas crises recorrentes são cada vez mais devastadoras para o povo de modo geral, mas especialmente aos trabalhadores, bem como aos docentes integrantes dessa categoria, dado que essas mudanças fortalecem o sistema econômico, provocam a expansão dos tentáculos capitalistas que sacrificam a classe trabalhadora e levam a expropriação dos direitos trabalhistas conquistados ao longo dos últimos séculos. Sem contar que todo esse processo provoca a falta de emprego e faz com que o trabalhador se submeta a atividades precárias para sobreviver.

É nesse contexto, segundo Fontes (ENTREVISTA...,2020), que o Estado tem se refugiado cada vez mais na bolha do capital. Enquanto isso, os trabalhadores estão submetidos a crescente violência física, desemprego, fome e degradação simbólica promovida pelas instâncias públicas que deveriam proteger e cuidar de todos/as, mas, ao contrário, ampliam as desigualdades sociais e a exploração dos sujeitos que trabalham, assim como colaboram para o aumento das estatísticas de exaustão, adoecimento e morte.

Diante disso, o que dizer dessas políticas que contribuem para a exclusão, exploração e precarização do trabalhador?

\section{As rupturas sociais geradas pelas políticas neoliberais}

Segundo Forrester (1997), estamos diante de certas políticas artificiais que pretendem permanecer mesmo diante das mazelas, destruições e aniquilações dos sujeitos. Para a autora, estamos presenciando, cotidianamente, de modo silenciado e apático, uma gravíssima mutação social e civilizatória. Essa insensibilidade proposital é instituída pelo con- 
texto neoliberal vigente que traz consigo uma postura impositiva para que sejamos silenciados e incapacitados de reconhecer e requerer direitos sociais igualitários. Pouco a pouco, os objetivos idealizados pelo sistema neoliberal vão instituindo e causando tensões sociais responsáveis pela miséria, precarização, exploração e aviltamento dos seres humanos.

\begin{abstract}
Mas, por trás de toda essa máscara, durante o transcurso desses subterfúgios oficializados, dessas pretensas 'operações' cuja ineficácia se conhece de antemão, desse espetáculo preguiçosamente deglutido, pesa o sofrimento humano, um sofrimento real, gravado no tempo, naquilo que tece a verdadeira história sempre ocultada. Sofrimento irreversível das massas sacrificadas; quer dizer, de consciências torturadas e negadas uma por uma (FORRESTER, 1997, p. 09).
\end{abstract}

Desse modo, percebe-se nitidamente o cumprimento de um modelo econômico que visa sustentar os braços do capitalismo, independentemente se a vida humana está em risco ou em extrema degradação. Aqui evidencia-se que o lucro, a competitividade e o descompromisso com as questões sociais são fatores que alimentam o sistema neoliberal. $O$ aumento das cifras, do capital e dos números estatísticos é o que realmente importa ao cumprimento das metas projetadas pelos neoliberais.

Forrester (1997, p. 24) ressalta que, com o desenvolvimento das premissas neoliberais, o trabalho se distanciou do propósito originário. Antes a acumulação de capital no liberalismo, o modelo de produção taylorista/fordista caracterizou-se pela produção em massa e consumo de massa. Essa estruturação possuía funções bem definidas e atribuídas com relação aos papéis estabelecidos nos postos de trabalho, ou seja, um grupo responsável pela administração, os gestores e os demais trabalhadores da produção como executores.

No entanto, tal modelo econômico de produção flexível e do trabalhador polivalente não se preocupa com as desigualdades sociais e os direitos já conquistados, pois, quanto maior a miséria, maior o lucro daqueles que estão dominando a economia, o trabalho e os salários. Mesmo porque o consumo de massa foi substituído pela produção de sofisticados produtos. Com os problemas sociais instaurados, abrem precedentes as especulações da economia privada com forte hegemonia e controle financeiro em todos os setores do Estado. Assim, para Forrester (1997, p. 29) há uma ampliação “[...] vertiginosa da quantidade de 
valores variados que elas podem abranger, dominar, combinar, duplicar sem se preocupar com leis e pressões que, num contexto assim mundializado, elas são capazes de contornar com facilidade".

Os avanços dessas economias privadas internacionais são autorizados pelo Estado que também fica sob controle de agências sem precedentes, sem ética, sem a mínima compaixão daqueles que são esmagados socialmente e, em geral, possuem um discurso de que tudo está cooperando para o bem de todos. Forrester (1997) ressalta que esses grupos econômicos privados são mais fortes do que as políticas, não se preocupam com as questões éticas e muito menos com a degradação humana que isso pode causar.

\begin{abstract}
Essas redes econômicas privadas, transnacionais, dominam então cada vez mais os poderes estatais; muito longe de ser controladas por eles, são elas que os controlam e formam, em suma, uma espécie de nação que, fora de qualquer território, de qualquer instituição governamental, comanda cada vez mais as instituições dos diversos países, suas políticas, geralmente por meio de organizações consideráveis, como o Banco Mundial, o FMI ou a OCDE (FORRESTER, 1997, p. 30).
\end{abstract}

São essas agências que possuem o maior poder e o controle de todas as dívidas que os Estados possuem. Para Forrester (1997, p. 32), a apresentação de falsas crises econômicas funciona como estratégia que contribui para o não revelar das artimanhas que o sistema neoliberal impõe. Assim, o procedimento tomado pela nova economia existe no sentido de devastar a sociedade e dizimar aqueles sujeitos considerados sem utilidade social, pois, para estes últimos, a miséria e o aviltamento serão o caminho para sua extinção total. Junto a isso, impõe-se a ideia de "flexibilização do trabalho" ou do trabalhador que parte de um conceito ligado "[...] as leis da concorrência, da competitividade, o ajustamento às regras econômicas internacionais - que são as da desregulação" (FORRESTER,1997, p. 32). Essa lógica promove a "subtração dos direitos sociais" constituídos historicamente por um povo, uma sociedade e uma nação.

A "fratura social" que leva a diminuição do valor humano é denominada por Forrester (1997, p. 34) como o resultado da falta de respeito, ausência do sentimento de humanidade e cuidado com o outro, forte exclusão das pessoas economicamente menos favorecidas que são em- 
purradas e colocadas à margem da sociedade para que não sejam vistas cotidianamente e, se possível, encarceradas por sistemas próprios. Esse olhar indiferente é proposital, naturalizado por uma estrutura econômica que é perspicaz em suas estratégias, sobretudo para causar uma ideia de que tudo está girando normalmente e que o curso da economia não foi afetado drasticamente desde a sua implantação. A autora nos chama a atenção para questões ligadas a essa indiferença humana, quando explicita que ela

[...] é quase sempre majoritária e sem freio. Ora, estes últimos anos foram, de certa maneira, campeões da inconsciência pacífica diante da instalação de um poder absoluto; campeões da história camuflada, dos avanços despercebidos, da desatenção geral. Desatenção tal que ela própria não é registrada. Desinteresse e falta de observação obtidos certamente por meio de estratégias silenciosas, obstinadas, que insinuaram lentamente seus cavalos de Tróia e souberam basear-se tão bem naquilo que propagam - falta de vigilância -, a ponto de elas próprias permanecerem despercebidas e, por isso mesmo, mais eficazes (FORRESTER, 1997, p. 41).

Ou seja, mantendo uma nação ocupada, explorada e alienada fica mais fácil se tornar indiferente aos problemas que emergem cotidianamente.

O sistema liberal atual é bastante flexível e transparente para adaptar-se às diversidades nacionais, mas bastante 'mundializado' para confina-las pouco a pouco no campo folclórico. Severo, tirânico, mas difuso, pouco identificável, disseminado por toda parte, esse regime que jamais foi proclamado detém todas as chaves da economia que ele reduz ao domínio dos negócios, os quais se apressam em absorver tudo o que ainda não pertencia à sua esfera (FORRESTER, 1997, p. 43).

Mesmo ameaçado a destruição, em dados momentos, esse sistema econômico manteve as suas estratégias fortes, nutrindo forças com base na exploração dos trabalhadores e visando conservar a acumulação de capital para as suas potências financeiras. Forrester (1997) distingue a potência do poder por serem diferentes. Para ela, a potência é forte e dificilmente muda de campo. Um exemplo disso é a "economia privada" 
e as "classes dirigentes", que às vezes podem até perder o poder, mas a potência, jamais. $O$ poder nem sempre possui estratégias fascinantes como a potência conseguiu conservar. A potência exercida pelo sistema neoliberal é fortalecida pela autoridade e o domínio de modo que nada se torna possível sem as suas ideias e a sua lógica econômica. Por esse motivo, todos os governos envolvidos pelo sistema se submetem as imposições fortemente arbitrárias do modelo neoliberal, pois

[...] seu domínio anima um sistema imperioso, totalitário em suma, mas, por enquanto, em torno de democracia e, portanto, temperado, limitado, sussurrado, calafetado, sem nada de ostentatório, de proclamado. Estamos realmente na violência da calma (FORRESTER, 1997, p. 45).

A autora nos instiga para uma luta e mobilização de classes contra esse tipo de política, cuja intenção é desviar a atenção das coisas necessárias, apresentando problemas inexistentes e falsas crises econômicas, pois, o objetivo desse sistema é continuar explorando o trabalhador de modo alienante e imperceptível, visando a manutenção das riquezas e o fortalecimento de suas potências neoliberais.

\section{As exigências impostas pelo capital à classe trabalhadora}

O autor norte-americano Richard Sennett (1999) no livro "A corrosão do caráter: consequências pessoais do trabalho no novo capitalismo" destacou que as diferentes mazelas no contexto social são oriundas do atual sistema econômico mundial capitalista moderno que tem exigido cada vez mais dos trabalhadores, cegando-os em rotinas extenuantes, levando-os a serem mais flexíveis, abertos, ágeis e submissos às diferentes mudanças, menos formais e legalistas. Exige-se que o trabalhador seja mais flexível no desenvolvimento do seu trabalho com maior instabilidade em sua trajetória profissional e que se enquadre em um processo fragmentado dos modos de produção, induzindo-o às diferentes especialidades que deva possuir para não ficar desempregado.

Sennett (1999) ressalta ainda que essa flexibilização e instabilidade podem provocar maior ansiedade no trabalhador e o levar a diversos caminhos que são capazes de contribuir para seu afligir e o submeter às precariedades laborativas. A maior consequência desse processo é a mudança do caráter pessoal que é possível acontecer com tal sistema de 
flexibilização do trabalhador, apontado pelo autor como um desdobramento mais amplo e que possui força para afetar a personalidade e os sentimentos intrapsíquicos dos sujeitos envolvidos.

O termo caráter concentra-se sobretudo no aspecto a longo prazo de nossa experiência emocional. É expresso pela lealdade e o compromisso mútuo, pela busca de metas a longo prazo, ou pela prática de adiar a satisfação em troca de um fim futuro. Da confusão de sentimentos em que todos estamos em algum momento em particular, procuramos salvar e manter alguns; esses sentimentos sustentáveis servirão a nossos caracteres. Caráter são traços pessoais a que damos valor em nós mesmos, e pelos quais buscamos que os outros nos valorizem (SENNETT, 1999, p. 10).

Desse modo, esse imediatismo cultivado na sociedade contemporânea pode levar as pessoas à impaciência, à incapacidade de colocar-se no lugar do outro, à exploração e à degradação humana, e, sobretudo, à alienação por meio de um sistema econômico que visa, de qualquer modo, o lucro à custa de vidas que são cotidianamente submetidas às arbitrariedades e às atrocidades impostas por uma classe dominante extremamente cruel.

Sennett (1999) salienta que a imprevisibilidade é um dos grandes destaques do atual sistema econômico, político e social. E isso corrobora com a derrocada diária e o desmoronamento dos direitos sociais constituídos a duras penas por um longo processo de mobilização. Direitos que foram fortalecidos por lutas, debates e pela construção histórico-social que, no entanto, são subtraídos por um grupo pertencente a uma classe dominante que quer manter o poder e as suas riquezas, explorando um pouco mais, a cada ano, os trabalhadores sem se importar com os altos índices de miséria no país.

O trabalhador atual é levado a obter uma formação que atende apenas as diversidades impostas pelo capital, mesmo que essas comprometam a sua qualidade de vida social e particular. Sennett (1999, p.21) afirma que:

[...] os líderes empresariais e os jornalistas enfatizam o mercado global e o uso das novas tecnologias como as características distintivas do capitalismo de nossa época. Isso é verdade, sim, mas não vê outra dimen- 
são da mudança: novas maneiras de organizar o tempo, sobretudo o tempo de trabalho.

A relação com o tempo, para Sennett (1999), é uma das questões que mais sofreram mudanças ao longo da história do homem. No lugar de uma vida social estável, deu-se abertura à convivência humana mais líquida e ausente de história cumulativa; assim, onde havia um trabaIho que perdurava gerações diversas, surgiram formações especializadas mais compatíveis que vieram suprir diferentes necessidades em um mercado de trabalho de espaços variáveis.

E, dentro desse contexto, a terceirização do trabalho está presente e se intensificando nas instituições criadoras dos meios de produção, bem como o trabalhador se vê crescentemente submetido aos processos de isenção dos seus direitos básicos de sobrevivência humana. $\mathrm{O}$ que gera toda essa mudança é, justamente, o capital com o seu fundamento no lucro, movimentado pelo mercado e a circulação de mercadorias. De acordo com Sennett (1999), atualmente, o trabalho é organizado em redes muito instáveis e não mais em pirâmides fundamentadas em contratos estruturados a longo prazo. Esse processo em rede exige ampla comunicação e importantes tecnologias para substituir significativamente o trabalho humano.

O autor aponta para o fato de que a corrosão da lealdade e da confiança do trabalhador é um dos princípios que mais tem contribuído para a não instituição de laços sociais a longo prazo, podendo ocorrer um enfraquecimento significativo nas relações de trabalho, pois, quando a confiança e o compromisso são abalados podem causar instabilidade, tanto em relação ao detentor dos meios de produção, como também no trabalhador e no seu vínculo trabalhista. O capital apregoa que o meIhor é manter esse distanciamento entre os sujeitos e as suas relações de trabalho, visando, sobretudo, o dinheiro e o lucro por estarem acima dessas questões sociais; em outras palavras, "[...] o distanciamento e a cooperação superficial são uma blindagem melhor para lidar com as atuais realidades que o comportamento baseado em valores de lealdade e serviço" (SENNETT, 1999, p.25).

Ainda em conformidade com Sennett (1999), "é a dimensão do tempo do novo capitalismo" que mais tem provocado problemas de ordem emocional e particular nos trabalhadores, sobretudo quando esses não estão no âmbito do trabalho. Essas adversidades podem afetar as relações sociais e familiares destes, sobrecarregando-os de culpa pela falta 
do tempo que foi extraído, de modo intencional, pelo sistema capitalista e que, de certo modo, não é explícito ao sujeito e o responsabiliza pelo presente obstáculo. Assim, são infindáveis os dilemas enfrentados pelos trabalhadores na atual sociedade. Os contratempos entre família e trabaIho são um desses problemas que podem provocar diferentes questionamentos, como por exemplo:

[...] se pode buscar objetivos de longo prazo numa sociedade de curto prazo? Como se pode manter relações sociais duráveis? Como pode um ser humano desenvolver uma narrativa de identidade e história de vida numa sociedade composta de episódios e fragmentos? [...] (SENNETT, 1999, p.27).

As respostas a esses questionamentos estão diretamente interligadas ao sistema econômico atual, que é o maior responsável pela exploração e alienação do trabalhador em relação aos processos de trabalho. A economia baseada no capital extrai tudo o que o sujeito possui e, com bases ideológicas, consegue ocultar todas as artimanhas organizadas para que não sejam explícitas essas arbitrariedades para não voltar negativamente aos seus próprios fundamentos.

Aportando-se em Adam Smith, Sennett (1999, p.39) destaca que "a circulação das moedas, bens e trabalho" contribuíram para o acúmulo das "riquezas das nações". Esse processo exigiu que as pessoas executassem, cada vez mais, um trabalho "especializado" e com o crescimento do mercado ampliou-se necessariamente a divisão do trabalho. Inicialmente, isso contribuiu na organização e ampliação da produção e do tempo do trabalhador, contudo, um pouco mais tarde, levou o sujeito ao trabalho especializado, provocando um absoluto tédio e um grande enfado pela repetição rotineira. Nesse caso, a rotina influencia na constituição do caráter humano e afeta a motivação e o interesse do sujeito em relação ao trabalho, fazendo-o alienar-se ao processo de produção e pensar cada vez menos nas operações mais complexas e dentro de uma totalidade. Esses males são ainda piores quando, na divisão do trabalho, fragmentam o trabalho manual do trabalho intelectual impondo o poder de um sobre o outro.

A política econômica atual, sobretudo a neoliberal, tem construído e disseminado a ideia de que o homem precisa ser mais flexível para enfrentar as adversidades que emergem do contexto social, atendendo o máximo possível o mercado capital com o seu trabalho mais di- 
nâmico e diverso. Pensando nisso, "[...] a sociedade hoje busca meios de destruir os males da rotina com a criação de instituições mais flexíveis. As práticas de flexibilidade, porém, concentram-se mais nas forças que dobram as pessoas" (SENNETT, 1999, p.53). Essa ideia tem sido cravada cotidianamente no meio social, exigindo que o homem seja mais aberto às transições.

\begin{abstract}
O sistema de poder que se esconde nas modernas formas de flexibilidade consiste em três elementos: reinvenção descontínua de instituições; especialização flexível de produção; e concentração de poder sem centralização. Os fatos que se encaixam em cada uma dessas categorias são conhecidos da maioria de nós, nenhum mistério; já avaliar a consequência deles, é mais difícil (SENNETT, 1999, p.54).
\end{abstract}

Reinventam novas formas de exploração do trabalho do homem, dando a ideia de que o regime de flexibilidade é necessário à formação profissional mais dinâmica, independente e fragmentada. Esse movimento está totalmente voltado à ampliação da produtividade dos sujeitos e ao lucro do capital. É uma constante e, dia após dia, mais comum os trabalhadores assumirem riscos, mesmo sabendo que poderão se submeter a perdas irreparáveis em sua carreira profissional e a uma estrutura de poder extremamente arbitrária, controladora e aniquiladora dos principais direitos sociais.

Para o autor, a inconstância e o risco contínuo no trabalho assumido pelo trabalhador, pode provocar uma corrosão no seu caráter humano e uma sensação de insegurança permanente mediante as incertezas apresentadas no novo contexto de trabalho. "A moderna cultura do risco é peculiar naquilo que não se mexer é tomado como sinal de fracasso, parecendo a estabilidade quase uma morte em vida [...]" (SENNETT, 1999, p.102).

É assim que o atual sistema econômico vem anunciando e implantando sutilmente as suas ideologias fixas em um sistema de produção que alimenta continuamente o capital. A condição de flexibilidade é um elemento fundamental na condução da economia neoliberal e pode ser uma das responsáveis pelas desigualdades no mercado de trabalho que atenua a disparidade entre aqueles que são bem remunerados e os que ficam à margem social com um salário baixíssimo. Sem contar que esse mercado tende a acolher os trabalhadores mais jovens e a os subordinar às diferentes condições 
de trabalho no cotidiano laboral, podendo, assim, descartar com maior facilidade aqueles que possuem idade elevada.

O que se vê nessa nova ordem econômica são inúmeros desafios que o trabalhador precisa enfrentar para a sua própria sobrevivência. O preconceito em relação ao trabalho das pessoas mais velhas, a submissão à baixa remuneração, à competitividade e à precarização do trabalho, bem como o individualismo, a flexibilização e a subordinação às regras impostas pelo modo de produção são problemas que o homem tem enfrentado cotidianamente no contexto social. Essa apreensão constante do sujeito, segundo Sennett (1999), pode provocar uma significativa "ansiedade" por ter que enfrentar tantos problemas originados pelo modo de produção que é regido por um sistema econômico pertencente a um "novo capitalismo", onde a apreensão "[...] é uma ansiedade sobre o que pode acontecer; é criada num clima que enfatiza o risco constante, e aumenta quando as experiências passadas parecem não servir de guia para o presente" (SENNETT, 1999, p. 114-115).

Sennett (1999) destaca que no contexto atual a ética do trabaIho é um dos grandes embates na organização social do trabalho. Para ele, a falta de organização do tempo no emprego/ofício acaba gerando essa superficialidade nas relações humanas. O serviço cooperativo e em equipe têm sido considerados a verdadeira ética do trabalho, mas, ainda assim, está permeado de aparências e fragilidades.

A moderna ética do trabalho concentra-se no tra-
balho de equipe. Celebra a sensibilidade aos outros;
exige 'aptidões delicadas', como ser bom ouvinte e
cooperativo; acima de tudo, o trabalho em equipe
enfatiza a adaptabilidade às circunstâncias. O traba-
Iho de equipe é a ética de trabalho que serve a uma
economia política flexível [...] O trabalho de equipe
é a prática de grupo da superficialidade degradante
(SENNETT, 1999, p.118).

O autor nos aponta que há contradições nesse processo coletivo, pois, é uma demanda que qualifica o trabalho em equipe, entretanto, nos mostra que nesse círculo podem ser desenvolvidas as mesmas arbitrariedades e imposições de um contexto diferente dessa organização do trabalho por não mudar a estrutura de poder do sistema de produção imposto pelo capital. 
O sistema capitalista vigente nos induz à autorresponsabilização pelos fracassos cotidianos, esse é um “[...] mercado em que o vencedor leva tudo [pois] é uma estrutura competitiva que predispõe ao fracasso grande número de pessoas educadas" (SENNETT, 1999, p.140). Diante disso, as estruturas de trabalho organizadas de modos mais flexíveis, contribuem para o desaparecimento das responsabilidades do capitalista em relação ao trabalhador. Muitas vezes, o trabalhador é culpado e levado a acreditar que o seu comportamento está inadequado ao que foi almejado pelo detentor dos meios de produção, podendo substituir os sujeitos por aqueles que se adequem aos princípios capitalistas e que se sujeitem à precarização no trabalho.

De acordo com os autores Neta et. al. (2020), a cada queda nos lucros capitalistas, surgem novas estratégias econômicas que objetivam a manutenção da hegemonia da classe dominante. Entretanto, os autores apontam que, mesmo diante das diferentes crises, o capital não perde a sua essência centrada na acumulação e exploração da classe trabalhadora. Ao contrário, são nas crises que o capital se fortalece e adquire novas estruturas para retomar sua função econômica com maior força e intensidade.

O neoliberalismo é mais um dos tentáculos da economia capitalista e se nutre nesse processo, ou seja, é um sistema ideológico que se atualiza e reatualiza constantemente para a continuidade da prática de exploração e expropriação do trabalho. Esse sistema está presente em diferentes políticas brasileiras desde os anos de 1990, bem como nas políticas voltadas ao campo da educação e contribui na intensificação da precarização do trabalho dos professores da educação básica e superior.

O neoliberalismo atinge a todos, a todas as regiões e setores, como entendem os autores Bastos e Cardozo (2014) quando analisam os impactos das mudanças econômicas e a presença desse sistema nas diretrizes educacionais organizadas na década de 1990 no Estado do Maranhão. Destacam que as diretrizes expressam princípios arbitrários, principalmente no que se refere à flexibilização do trabalho e aos baixos salários dos docentes submetidos aos contratos determinados. $\mathrm{Ou}$ seja, a pesquisa deixa evidente a existência da precarização no trabalho docente no contexto do Sistema da Rede Pública de Ensino na referida região. Isso reafirma o quanto é forte a ideologia neoliberal e como os seus tentáculos estão presentes em diferentes sistemas da sociedade. Mostra-nos como a classe trabalhadora, bem como os trabalhadores 
docentes, estão se sujeitando para continuar sobrevivendo a uma economia devastadora e de controle econômico que visa o lucro e o coloca acima das vidas humanas.

Teixeira e Coutinho (2012) demonstraram em estudo que desde a sua expansão no Brasil, a perspectiva neoliberal tem buscado defender a qualquer custo uma educação e formação docentes que atendam demandas específicas do capital. Nesse entendimento, a educação deve ser desenvolvida como um instrumento para difundir os conceitos ideológicos da concepção neoliberal e que seja necessário exigir um processo disciplinar alinhado aos interesses econômicos mundiais e de suas agências de fomentos. Contudo, para que isso possa ser efetivado, essa nova forma de economia neoliberalista busca defender uma formação de força de trabalho que consiga ser adequada às demandas produtivas, pois, é um tipo de ação que requer conhecimento acerca das tecnologias e entendimento sobre o recente processo de organização do trabaIho. Essa perspectiva ideológica neoliberal procura defender e implantar uma nova forma de educação que possa perpetuar as artimanhas do sistema capitalista, especialmente, em favor da continuação do seu domínio em relação ao mercado e ao processo produtivo.

Nesse processo, não podemos descuidar de discutir, compreender, interpretar e analisar cada vez mais a mercantilização da educação em geral que se completa com as privatizações institucionais, mas que seu caminho vem sendo construído como formação profissional, estruturada e mantida na esfera pública, como alerta Ramos (1995, p. 199), "[...] o Estado mantém-se como financiador da educação pública [...], mas sua concepção, regulação, orientação e adequação [são realizadas] na esfera privada e em favor dela."

Consideramos a questão da mercantilização da educação de relevância, uma vez que se caracteriza por uma estruturação de planejamento, objetivos, metas, normas, programas de qualidade total, práticas estas impostas pela lógica da sociabilidade do capital, mercado e ideologia produtivista do trabalho a qualquer preço, práticas estas há muito determinadas e cobradas nas mais variadas formas, com avaliações externas e autoavaliações dos servidores públicos, dentre eles os da educação.

O capital tenta alcançar, sempre, um maior nível de produtividade, afetando, com isso, a natureza das rotinas do trabalho. São evidentes as exigências da 
nova base tecnológica que, por um lado, requer maior qualificação com relação à concepção e à execução de determinadas atividades, introduzindo um novo e acelerado ritmo e exigindo uma multiplicidade de operações concatenadas de previsão e de decisão, com um alto nível de atenção (CARNEIRO, 1998, p 14).

A profissão professor/educador/servidor público é sistematicamente desvalorizada pela grande mídia que a tem atacado e amedrontado com constantes ameaças de privatizações em evidente valorização da prestação do serviço privado, conceituado por essas mídias em atendimento aos objetivos do capital financeiro e dos grupos internacionais como incomparavelmente superior e eficiente, em todos os sentidos, pelo trabalho que realizam nas áreas sociais, especificamente na educação. A desqualificação do público e o enaltecimento do privado abrange aspectos que vão de suas técnicas, produção de ciência, produtividade do trabalho, competência dos trabalhadores, gerenciamento, chegando até mesmo à "probidade". Tais mídias se utilizam de um discurso articulado, insistente, cotidiano e mentiroso que, repetido há décadas, resultou em credibilidade por parte de uma parcela significativa da sociedade, o que corroborou no "asfixiamento" do público via cortes de verbas, extinção de grande número de bolsas de estudo e PEC da Morte (Emenda Constitucional 95/2016) - que sucateia o público, atende à lógica das empresas privadas que vem sendo imposta no campo educacional - e que se trata da mesma lógica da mercantilização que prepara a aceitação social para a privatização. A cobrança de mensalidades é uma das últimas medidas dos processos de privatizações, assim, uma vez que a lógica do trabalho e suas práticas no sistema privado já estão consolidadas, o "quantitativismo" toma conta de todos os âmbitos da vida e, com tantas demandas, os professores não conseguem refletir sobre as reais contradições da produtividade de sua profissão. Sabemos que produtividade é igual a maior exploração do trabalho e que essa palavra é mágica para o capital, mas o que realmente significa para o trabalhador é a expropriação brutal de trabalho excedente.

Entretanto, conhecendo os mecanismos ideológicos do neoliberalismo, há uma urgente necessidade de lutar por uma educação humana e emancipadora, especialmente conclamar por um processo educativo público que contribua na formação de sujeitos que, por intermédio dela, possam defender uma sociedade justa, solidária e igualitária. 
Em suma, seria necessária uma formação educativa escolar que visasse o desenvolvimento da consciência do sujeito para "[...] um futuro emancipador, não-retrogrado, [...] mais coletivo, igualitário, inclusivo, democrático, representativo [...] e responsável pelos bens públicos" (RAMALHO, 2018, p. 296).

\section{Considerações finais}

O neoliberalismo é uma teoria que se impôs como caminho único desde a crise de 1970 (mais conhecida como crise do petróleo) e como processo de recuperação da acumulação de capital ao nível mundial. É um modelo teórico econômico do capital financeiro que se contrapôs ao Estado do Bem-Estar Social que planejou e aperfeiçoou, contínua e meticulosamente, estratégias de cortes intermináveis nas conquistas dos trabalhadores por salários, direitos trabalhistas, aposentadorias, educação, saúde, habitação, bem como interpôs a destruição dos sindicatos, privatizações, desemprego, precarização do trabalho, terceirizações.

Seu objeto é a apropriação sem limites dos recursos dos fundos públicos para priorizar as demandas da sociabilidade do capital e a inviabilização dos investimentos sociais, jogando na pobreza e na miséria a maior parte dos trabalhadores no mundo. Haja vista que, no Brasil, a estratégia genocida de um governo fascista frente ao enfrentamento do coronavírus, pandemia mundial, na pessoa do presidente Jair Messias Bolsonaro, não só tem se mostrado uma das mais contundentes e negacionistas desta realidade, como também não impetrou atitudes sequer de provimento, tampouco se condoeu com o número sempre crescente de mortos que passam dos 20000 mil e os mais de 300000 mil infectados, o que evidencia quão supérflua é a população em sua ótica. Sua preocupação é o término do isolamento social - única via de se preservar vidas que cientificamente se conhece - para abrir a economia e evitar mais prejuízos financeiros.

Os brasileiros se defrontam com a crise econômica que já existia agora agravada pela pandemia e com um governo militarizado do capital financeiro, em que as reformas da Previdência e da legislação trabalhista, segundo explicitado por Souza (2020), compõem um quadro onde a escravidão, de fato, nunca foi abolida.

A noção humanística e iluminista do sujeito racional capaz de deliberação e escolha vem sendo substituída pela construção de um 
novo modelo de indivíduo neoliberal, consumista, digital, computacional, presentificado e que acredita poder viver sem mediações com os outros - é ele que faz acontecer.

Ramalho (2018, p. 293-294) mostra que dentro desse processo, há ideologias e ações conservadoras, ou seja, "[...] elitistas, antidemocráticas, exclusivistas e claramente opressoras" que agem em função da perpetuação desse sistema "em nome da eficiência e do lucro"

Assim, é preciso assumir o risco de compreender a história como fundamento de enfrentamento das mazelas provocadas pelo presente sistema neoliberal que é um grande difusor das desigualdades sociais, destruidor de direitos e voltado para preservar as riquezas de uma classe dominante entreguista e perversa. De maneira que concordamos com Ramalho (2018), lutamos evidentemente sabendo que a nossa esperança é equilibrista, mas certos de que como educadores, não podermos desistir de contribuir na construção da justiça social.

\section{Referências}

ANDERSON, P. Balanço do Neoliberalismo. In.: SADER, E.; GENTILI, P. (orgs.) Pós-neoliberalismo: as políticas sociais e o Estado democrático. Rio de Janeiro: Paz e Terra, 1995, p. 9-23.

BASTOS, J. D. B.; CARDOZO, M. J. A Precarização do Trabalho Docente no Maranhão: considerações sobre o contrato temporário. Rev. Educação e Emancipação, São Luís-MA, v. 7, n. 1, jan./jun. 2014. Disponível: http://www.periodicoseletronicos.ufma.br/index.php/ reducacaoemancipacao/article/view/3312/2612. Acesso em: 23 maiO 2020.

BÔAS, B. V. Brasil já tem mais de 5 milhões de crianças na extrema pobreza. Valor Econômico, 7 dez. 2018. Disponível em: https://www. valor.com.br/brasil/6016071/brasil-ja-tem-mais-de-5-milhoes-decriancas-na-extrema-pobreza. Acesso em: abr. 2019.

BRASIL. Emenda Constitucional n 95, de 15 de dezembro de 2016. Altera o Ato das Disposições Constitucionais Transitórias, para instituir o Novo Regime Fiscal, e dá outras providências. Diário Oficial da União: Brasília, DF, 15 dez. 2016. Disponível em: http://www.planalto.gov.br/ ccivil_03/constituicao/emendas/emc/emc95.htm. Acesso em: 9 abr. 2019 
CARNEIRO, M. E. F. A revolta camponesa de Trombas e Formoso. Goiânia: Editora UFG, 1988.

CHAUÍ, M. Sob o signo do neoliberalismo. In.: CHAUÍ, Marilena. Cultura e democracia: o discurso competente e outras falas. 13 ed. São Paulo: Cortez, 2011, p.311-339.

SOB Bolsonaro, Petrobras abre mão de refinar 1,1 milhão de barris por dia. Diário do Centro do Mundo, 20 abr. 2019. Disponível em: https:// www.diariodocentrodomundo.com.br/sob-bolsonaro-petrobras-abremao-de-refinar-11-milhao-de-barris-dia/. Acesso em: 9 abr. 2019.

ENTREVISTA: Coronavírus e a crise do capital. Entrevistada: Vírginia Fontes. Andes, 16 abr. 2020. Disponível em: https://www.andes.org.br/ conteudos/noticia/cORONAVIRUS-e-a-cRISE-dO-cAPITAL1. Acesso em: 9 abr. 2020.

FORRESTER, V. O horror econômico. Tradução: Álvaro Lorencini. São Paulo: Editora da Universidade Estadual Paulista, 1997.

CASTRO NETA, A. A. et. al. Contextos da Precarização Docente na Educação Brasileira. Revista Exitus, Santarém/PA, v. 10, p. 1-25, 2020. Disponível em: http://www.ufopa.edu.br/portaldeperiodicos/ index.php/revistaexitus/article/view/1261. Acesso em: 22 mai. 2020. DOI: http://dx.doi.org/10.24065/2237-9460.2020v10n0ID1261

PARADELLA, R. Desemprego sobe para 12,4\% e população subutilizada é a maior desde 2012. Agência IBGE Notícias. 31 maio 2019. Disponível em: https://agenciadenoticias.ibge.gov.br/agencia-noticias/2012agencia-de-noticias/noticias/24110-desemprego-sobe-para-12-4e-populacao-subutilizada-e-a-maior-desde-2012. Acesso em: 5 mar. 2019.

POCHMANN, Marcio. O receituário de Temer e Bolsonaro e a regressão das relações de trabalho. Rede Brasil Atual, 26 nov. 2018. Disponível em: https://www.redebrasilatual.com.br/revistas/146/o-receituario-detemer-e-bolsonaro-e-a-regressao-das-relacoes-de-trabalho. Acesso em: 19 abr. 2019.

RAMALHO, T. Vendo de perto o bicho na toca: expondo o impostor neoliberal na educação. Rev. Educação e Emancipação, São Luís- MA, v.11, n.3, Dossiê Temático, set./dez. 2018. Disponível em: http://www. periodicoseletronicos.ufma.br/index.php/reducacaoemancipacao/ 
article/view/9772. Acesso em: 24 abr. 2020. DOI: http://dx.doi. org/10.18764/2358-4319.v11n3p291-314.

RAMOS, M. N. Do ensino técnico à formação tecnológica: historicidade das políticas públicas dos anos 90. Niterói, 1995. Dissertação (Mestrado em Educação) - Universidade Federal do Rio de Janeiro, Niterói, 1995.

SENNETT, Richard. A corrosão do caráter: consequências pessoais do trabalho no novo capitalismo. Rio de Janeiro: Record, 1999.

TEIXEIRA, F. M.; COUTINHO, A. F. Neoliberalismo e Educação: novos conceitos e estratégias de disciplinamento e suas influências para a formação de educadores. Rev. Educação e Emancipação, São Luís- MA, v.5, n.2,jul./dez.2012. Disponível em:<http://www.periodicoseletronicos. ufma.br/index.php/reducacaoemancipacao/article/view/3244>. Acesso em: 23 mai. 2020.

Recebido em: Julho/2019

Aceito em: Março/2020 